\title{
Usefulness of Ultrasound Devices in Facial Plastic Surgery
}

\author{
Won Lee, $\mathrm{MD}, \mathrm{PhD}^{1}$ \\ Wook Oh, MD ${ }^{2}$ \\ Hyun Jun Park, $\mathrm{MD}^{2}$
}

${ }^{1}$ Yonsei E1 Plastic Surgery Clinic, Anyang, Korea

${ }^{2}$ Maylin Clinic, Seoul, Korea

Received April 6, 2021

Accepted April 19, 2021

\footnotetext{
Correspondence

Won Lee

Yonsei E1 Plastic Surgery Clinic, Anyang

14072, Korea

E-mail: e1clinic@daum.net

https://orcid.org/0000-0001-7411-0198

(C) Korean Society for Laser, Dermatology and Trichology

(c) This is an open access article distributed under the terms of the Creative Commons Attribution NonCommercial License (http://creativecommons.org/ licenses/by-nc/4.0) which permits unrestricted noncommercial use, distribution, and reproduction in any medium, provided the original work is properly cited.
}

The use of ultrasound technology in aesthetic fields is common. The proper use thereof can help plastic surgeons achieve satisfactory outcomes. The study was designed to outline the use of ultrasound technology devices in plastic surgery. The PubMed database was searched for articles reporting on the use of diagnostic ultrasound, microfocused ultrasound technology, and non-focused ultrasound technology. Doppler ultrasound technology has found use in detecting arteries of the face. Emitting thermal energy, microfocused ultrasound has been used to elicit skin tightening and fat reduction effects. The use of non-focused ultrasound technology to achieve cellular level effects has garnered greater interest. Understanding of different applications of ultrasound technology could help with improving treatment results in facial plastic surgery.

\section{Key words}

Ultrasound technology, Microfocused ultrasound, Non-focused ultrasound, HIFU, Hyaluronic acid filler 


\section{AESTHETICS}

\section{INTRODUCTION}

In recent years, energy-based devices have been increasingly used in fields of dermatology, aesthetic medicine, and plastic surgery. In plastic surgery, laser and non-surgical fat removal devices are popular [1]. Among these devices, those emitting ultrasound waves are most widely used because of their safety: ultrasound devices emit high frequency sound waves that pose no harm to facial tissues. Recently, research on the use of ultrasound in plastic surgery has focused on the detection of facial features beneath the surface of the skin, especially when performing filler injections and thread lifting, which are considered blind techniques. High-intensity focused ultrasound technology has been used to achieve skin tightening and face contouring. Non-focused ultrasound technology has also found use. In this study, we aimed to review the literature on the use of ultrasound technology and to propose possible application thereof in plastic surgery.

\section{MATERIALS AND METHODS}

The PubMed database was searched for the following terms in April 2021: "ultrasound hyaluronic acid filler", "ultrasound thread lifting," "microfocused ultrasound," and "non-focused ultrasound." We excluded articles not written in English, that described the use of ultrasound devices for non-aesthetic purposes, that used ultrasound to merely confirm the presence of filler, that were experimental in design, that focused on the hands and neck, and that comprised ophthalmic ultrasound studies. In total, 338 articles were found, and after applying the exclusion criteria, 23 articles were finally reviewed.

\section{RESULTS}

\section{Ultrasound technology for visualization}

For ultrasound devices, $1 \mathrm{~Hz}$ means $1 \mathrm{cycle} / \mathrm{sec}$ and indicates how many pulses are made during 1 second. For tissue visualization, settings of $8 \mathrm{MHz}$ to $20 \mathrm{MHz}$ are typically used, and the use of $8 \mathrm{MHz}$ provides a depth of visualization of approximately $50 \mathrm{~mm}$. At $20 \mathrm{MHz}$, a depth of $10 \mathrm{~mm}$ can be visualized (Fig. 1).

Upon emitting ultrasound energy to tissue, waves are reflected to the probe at 90 degrees. During the procedure, however, the energy can be absorbed by the tissue or scattered. When the attenuated energy, such as absorbed or scattered energy, is high, images are not obtainable. Ultrasound at a relatively high frequency leads to more attenuation, and as such, a lower frequency is needed to detect deeper structures.

The mechanism of the treatment effects elicited by ultrasound energy relies on repetitive electric stimulations. These stimulations exert compression and rarefaction pressure, due to piezoelectric effects (Fig. 2). When ultrasound energy interacts with human tissue, attenuation of ultrasound energy induces thermal changes. Ultrasound devices for diagnosis generate minimal thermal energy and pose no harm to human tissue. However, some devices, such as high-intensity focused ultrasound devices, can emit an intensity up to $5,000 \mathrm{~W} / \mathrm{cm}^{2}$ and can elicit tissue temperatures up to $60^{\circ} \mathrm{C}$. The mechanism of diagnostic ultrasound is seen in Fig. 3.

\section{1) Vascular mapping for injections}

The most tragic complications of filler injections, including ocular complications, are related to the vascularity in
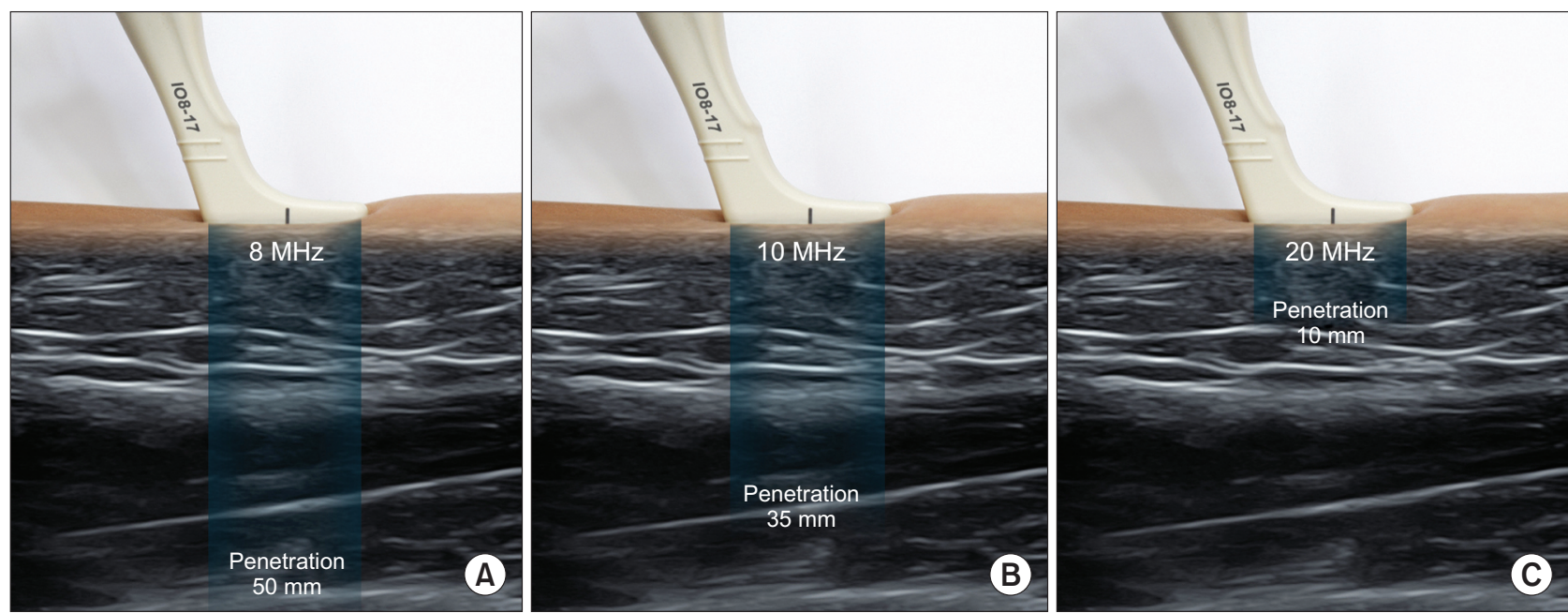

Fig. 1. Different depths of visualization with different ultrasound frequencies. 

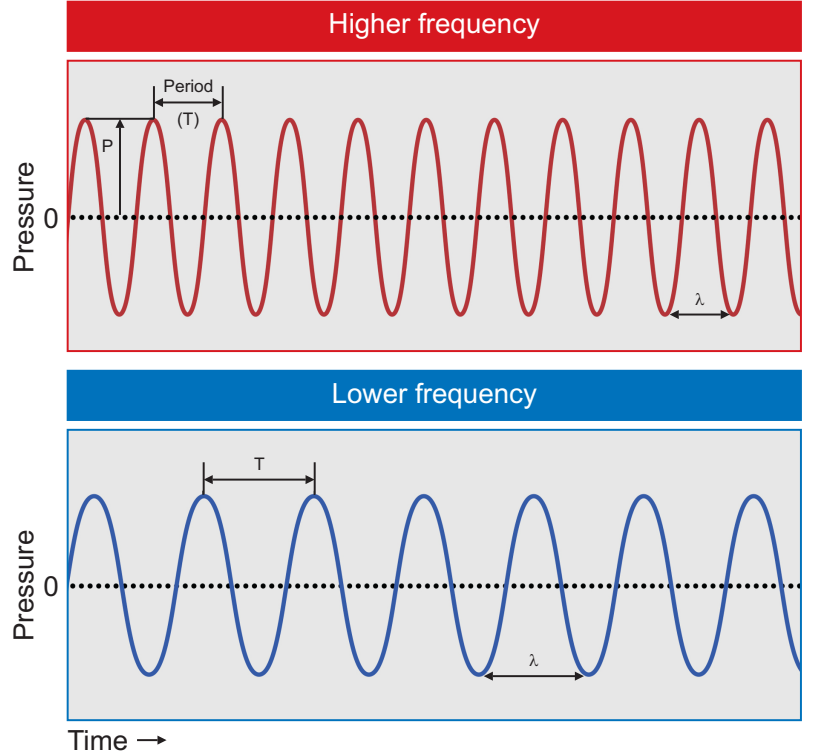

P: Pressure $\quad \gamma$ : Wavelength $\quad$ f: Frequency $\quad$ T: Period

Fig. 2. Depiction of ultrasound frequencies. High frequencies are better for detecting dermal layers; low frequencies are better for detecting deeper layers. Repetitive compression pressure and rarefaction pressure occur with ultrasound energy.

the face. During injection procedures, Doppler ultrasound can be used to detect arteries and vessels: Facial arteries can be detected during nasolabial fold correction [2]. The supratrochlear artery can be detected during correction of glabellar frown lines [3]. The frontal branch of the superficial temporal artery also can be detected [4]. Additionally, the dorsal nasal artery can also be detected during nose augmentation by filler injections [5]. The use of Doppler ultrasound to locate vessels that could be potentially harmed during filler injections can help prevent vascular complications [6].

\section{2) Detection of filler complications}

Doppler ultrasound can also be used to detect complications from filler injections. Vascular complications, such as those associated with compression [7] or embolism [8], can be diagnosed upon vessel detection in all areas of the face, such as the tear trough, nose, temple, and lips [9]. Ultrasound can also be used to detect palpable nodules [10] and to determine which kinds of filler have been injected [11]. Research has shown that the amount, location, and depth of previous injected filler can be identified for precise intralesional delivery of hyaluronidase to dissolve filler [12].

\section{Microfocused ultrasound technology}

Microfocused ultrasound (MFU) technology facilitates the precise delivery of acoustic energy to targeted tissue,

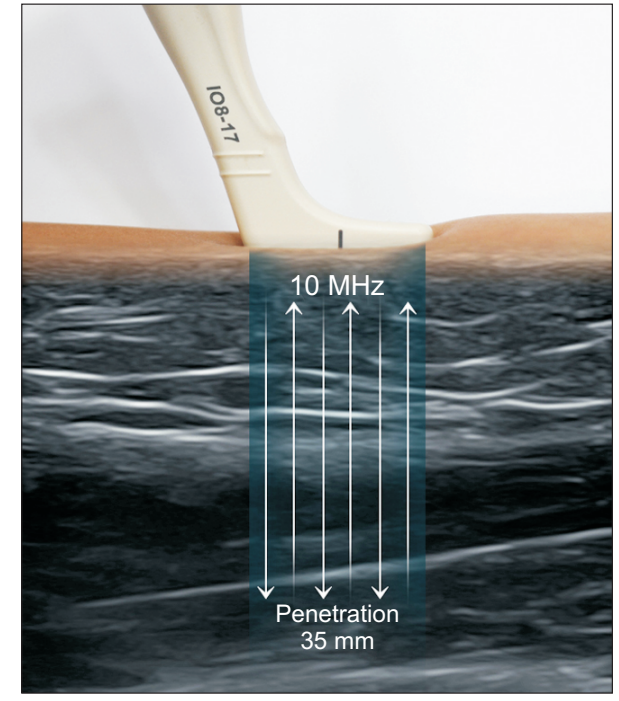

Fig. 3. Mechanism of diagnostic ultrasound. An ultrasound probe sends signals at a right angle and receives signals after the energy is reflected. The energy is attenuated (i.e., scattered or absorbed) during energy transfer, eliciting thermal effects.

with minimal damage to surrounding structures. MFU is able to effectively disrupt tissue by exploiting the transformation of acoustic energy into thermal damage. MFU can be focused on subcutaneous tissue, where temperatures briefly increase beyond $60^{\circ} \mathrm{C}$, producing small thermal coagulation points to a depth of up to $5 \mathrm{~mm}$ within the midto-deep reticular layer of the dermis and subdermis [13]. These thermal changes shrink the tissue for skin tightening effects. The target layer of the face for skin tightening would be the musculocutaneous layer [14]. When applied at the subcutaneous fat layer, ultrasound thermal energy can be applied to elicit adipose cell destruction [15]. Histologic reports have shown that MFU targets subcutaneous adipose tissue [16]. The mechanism of MFU is outlined in Fig. 4. Dual-depth focused ultrasound can also be used for skin tightening [17].

\section{Non-focused ultrasound technology}

Non-focused ultrasound can also be used in facial plastic surgery, although reports thereof in the literature are scarce. Whereas high frequency ultrasound can reach a depth of more than $50 \mathrm{~mm}$ for diagnosis and vascular visualization and high-intensity focused ultrasound can be used to generate thermal changes in target tissue, non-focused ultrasound can be used to target the cellular level. Matrix metalloproteinases (MMPs) are known to be important in both chronological and photo-induced skin ageing [18], and heat shock proteins (HSPs) are important in fibroblast activity and collagen production [19]. Interestingly, decreasing the production of HSPs has been found to be a possible 


\section{AESTHETICS}
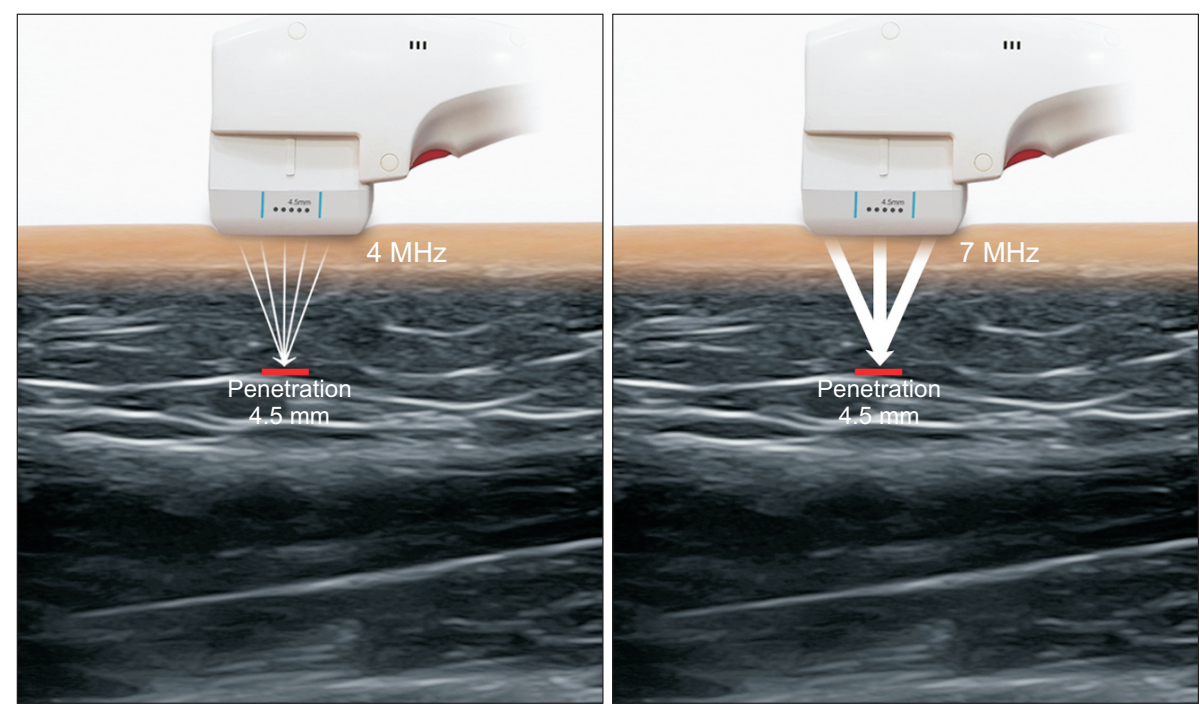

Fig. 4. Use of microfocused ultrasound on the skin. Microfocused ultrasound technology generates thermal coagulation in the musculocutaneous layer for skin tightening effects or destroys fat cells in the subcutaneous layer for face contouring. Ultrasound energy at $7 \mathrm{MHz}$ reaches a shallower depth than $4 \mathrm{MHz}$, and thus, a higher intensity is needed to reach the same depth.
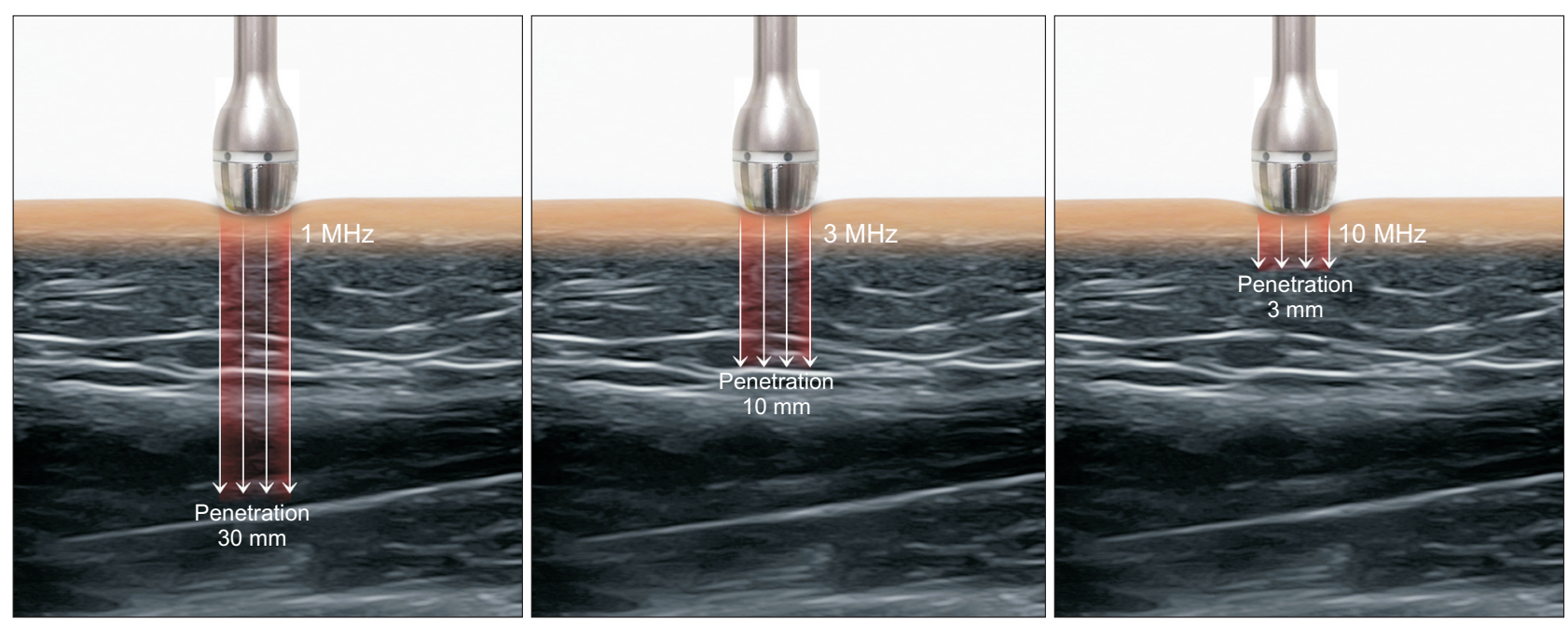

Fig. 5. The use of non-focused ultrasound energy to generate tissue changes. The probe (1 MHz, $3 \mathrm{MHz}, 10 \mathrm{MHz}$ ) is from Intense Ultra (lonto Comed, Germany). Energy at $10 \mathrm{MHz}$ emits a large number of acoustic waves, but the depth is relatively shallow. Therefore, high intensity is required to overcome energy attenuation from scattering and absorption.

target for reducing the signs of ageing [20]. Modulation of both MMPs and HSPs could be possible with non-focused ultrasound technology [21]. The use of non-focused ultrasound energy is outlined in Fig. 5.

\section{DISCUSSION}

Ultrasound technology is being widely used in aesthetic fields for detecting arteries of the face, for detecting possible filler complications, for eliciting therapeutic thermal damage to the musculoaponeurotic and subcutaneous layers, and for anti-ageing by stimulating connective tissue restoration. Several other potential uses for ultrasound technology are proposed below.
One potential use for ultrasound technology is in threedimensional restoration of the facial vasculature. Although doppler ultrasound can detect arteries of the face, it is quite difficult to learn how to use ultrasound at the face because of its two-dimensional images. Future technology could make three-dimensional images more accessible and in real time for safer injection procedures. Another potential use is for microfocused ultrasound in procedures to reduce submental fat. Ultrasound energy is transferred to water content easily. Applying MFU in combination with tumescent solution and/or other solutions, such as fat dissolving solutions, can induce larger thermal injury zones and potentially greater fat reductions [22]. Thus, for patients desiring less invasive techniques, MFU for fat reduction could prove pref- 
erable over conventional liposuction. A third potential use is in post-operative swelling and preoperative treatment. Stimulating connective tissue restoration, non-focused ultrasound technology might help reduce inflammation and post-operative swelling. This could potentially be applied to conventional face lift operations, thread lifting, and microfat grafting. Further studies are warranted to assess postoperative swelling at the cellular level. Ultrasound also can be used for preoperative treatment to restore connective tissue balance. Use of 3-MHz non-focused ultrasound energy can reach the subcutaneous fatty layer and might help facilitate smoother injections or surgical dissection. One final potential use for ultrasound technology is in the elimination of cellulite. Cellulite is a common condition caused by abnormal tethering of fat strands to the subcutaneous tissues. Research has shown that high-intensity focused ultrasound cavitation causes architectural changes in subcutaneous fat tissue, disrupting the cellulite [23]. Another interesting report mentioned the use of shock wave treatment for cellulite [24]: Acoustic wave therapy originates from shock wave technology successfully used for over 30 years in urology. Ultrasound devices, such as MFU or non-focused ultrasound, might also find use for treating cellulite and other conditions, such as lipedema, striae, or capsular fibrosis after breast operations.

\section{CONCLUSION}

Ultrasound technology is widely used in aesthetic fields, and many possible applications thereof in several plastic surgery fields await study. Understanding of action mechanisms for ultrasound technology should be established to use better surgical and/or minimal invasive results.

\section{CONFLICT OF INTEREST}

No potential conflict of interest relevant to this article was reported.

\section{REFERENCES}

1. The Aesthetic Society's Cosmetic Surgery National Data Bank: Statistics 2019. Aesthet Surg J 2020;40(Suppl 1):1-26.

2. Lee W, Kim JS, Moon HJ, Yang EJ. A safe Doppler ultrasoundguided method for nasolabial fold correction with hyaluronic acid filler. Aesthet Surg J. Forthcoming 2020. https://doi.org/ 10.1093/asj/sjaa153

3. Lee W, Moon HJ, Kim JS, Yang EJ. Safe glabellar wrinkle correction with soft tissue filler using Doppler ultrasound. Aesthet Surg J. Forthcoming 2020. https://doi.org/10.1093/asj/ sjaa197

4. Lee W, Moon HJ, Kim JS, Chan BL, Yang EJ. Doppler ultrasound-guided thread lifting. J Cosmet Dermatol 2020;19: 1921-7.

5. Moon HJ, Lee W, Do Kim H, Lee IH, Kim SW. Doppler ultrasonographic anatomy of the midline nasal dorsum. Aesthetic Plast Surg. Forthcoming 2020. https://doi.org/10.1007/ s00266-020-02025-1

6. Lee W. Prevention of hyaluronic acid filler-induced blindness Dermatol Ther 2020;33:e13657.

7. Lima VGF, Regattieri NAT, Pompeu MF, Costa IMC. External vascular compression by hyaluronic acid filler documented with high-frequency ultrasound. J Cosmet Dermatol 2019;18: 1629-31.

8. Schelke LW, Velthuis P, Kadouch J, Swift A. Early ultrasound for diagnosis and treatment of vascular adverse events with hyaluronic acid fillers. J Am Acad Dermatol. Forthcoming 2019. https://doi.org/10.1016/j.jaad.2019.07.032

9. Jaguś D, Skrzypek E, Migda B, Woźniak W, Mlosek RK. Usefulness of Doppler sonography in aesthetic medicine. J Ultrason 2021;20:e268-72.

10. Mlosek RK, Migda B, Skrzypek E, Stoboda K, Migda M. The use of high-frequency ultrasonography for the diagnosis of palpable nodules after the administration of dermal fillers. J Ultrason 2021;20:e248-53.

11. Urdiales-Gálvez F, De Cabo-Francés FM, Bové I. Ultrasound patterns of different dermal filler materials used in aesthetics. J Cosmet Dermatol. Forthcoming 2021. https://doi.org/ 10.1111/jocd.14032

12. Schelke LW, Decates TS, Velthuis PJ. Ultrasound to improve the safety of hyaluronic acid filler treatments. J Cosmet Dermatol 2018;17:1019-24.

13. Fabi SG. Noninvasive skin tightening: focus on new ultrasound techniques. Clin Cosmet Investig Dermatol 2015;8:4752.

14. White WM, Makin IR, Barthe PG, Slayton MH, Gliklich RE. Selective creation of thermal injury zones in the superficial musculoaponeurotic system using intense ultrasound therapy: a new target for noninvasive facial rejuvenation. Arch Facial Plast Surg 2007;9:22-9.

15. Kwon TR, Im S, Jang YJ, Oh CT, Choi EJ, Jung SJ, et al. Improved methods for evaluating pre-clinical and histological effects of subcutaneous fat reduction using high-intensity focused ultrasound in a porcine model. Skin Res Technol 2017; 23:194-201.

16. Gadsden E, Aguilar MT, Smoller BR, Jewell ML. Evaluation of a novel high-intensity focused ultrasound device for ablating subcutaneous adipose tissue for noninvasive body contouring: safety studies in human volunteers. Aesthet Surg J 2011; 31:401-10 


\section{AESTHETICS}

17. Baumann L, Zelickson B. Evaluation of micro-focused ultrasound for lifting and tightening neck laxity. J Drugs Dermatol 2016;15:607-14.

18. Fisher GJ, Kang S, Varani J, Bata-Csorgo Z, Wan Y, Datta S, et al. Mechanisms of photoaging and chronological skin aging. Arch Dermatol 2002;138:1462-70.

19. Dams SD, de Liefde-van Beest M, Nuijs AM, Oomens CW, Baaijens FP. Heat shocks enhance procollagen type I and III expression in fibroblasts in ex vivo human skin. Skin Res Technol 2011;17:167-80.

20. Calderwood SK, Murshid A, Prince T. The shock of aging: molecular chaperones and the heat shock response in longevity and aging--a mini-review. Gerontology 2009;55:550-8.
21. Kruglikov IL, Sontag W. Ultrasound of $10 \mathrm{MHz}$ frequency as a novel strategy for skin anti-aging therapy. Med Hypotheses 2010;74:620-1.

22. Lee S, Kim HJ, Park HJ, Kim HM, Lee SH, Cho SB. Morphometric analysis of high-intensity focused ultrasound-induced lipolysis on cadaveric abdominal and thigh skin. Lasers Med Sci 2017;32:1143-51.

23. Moravvej H, Akbari Z, Mohammadian S, Razzaghi Z. Focused ultrasound lipolysis in the treatment of abdominal cellulite: an open-label study. J Lasers Med Sci 2015;6:102-5.

24. Siems W, Grune T, Voss P, Brenke R. Anti-fibrosclerotic effects of shock wave therapy in lipedema and cellulite. Biofactors 2005;24:275-82. 